\title{
Um Pouco de Resistência e Luta Não Faz Mal à Ninguém: interfaces pedagógicas e movimento interfaces como espaço de formação contra hegemônico
}

\author{
Un Poco de Resistencia y Lucha no Hace Mal a Nadie: interfaces \\ pedagógicas y movimiento interfaces como espacio de formación contra
}

hegemónico

\begin{abstract}
A Little of Strength and Struggle Does Not Have Anything to Anyone: pedagogical interfaces and movement interfaces as a training space
\end{abstract} against hegemonic

\author{
Felipe Treviso Bresolin ${ }^{1}$ \\ Samuel Crissandro Tavares Ferreira ${ }^{2}$ \\ Vânia Alves Martins Chaigar ${ }^{3}$
}

\begin{abstract}
Resumo
O presente trabalho tenta organizar e sistematizar uma relação do evento Interfaces Pedagógicas e de seu desdobramento chamado Movimento Interfaces, com as atividades e participações de movimentos de resistência e de luta na cidade. É importante ressaltar que o Interfaces Pedagógicas desde o ano de 2013 se coloca na perspectiva de fortalecer as licenciaturas e o diálogo das mesmas na universidade e seus espaços, ao mesmo tempo que propõem uma interlocução com os espaços para além da universidade. O Movimento Interfaces aparece como complemento a partir do ano de 2016, para dar continuidade as discussões e reflexões demandadas. Dito isso, o trabalho tenta abordar de forma crítica às contribuições que foram trazidas aos eventos pelos movimentos sociais inseridos na cidade e que podem nos alertar quanto a epistemologia de resistências e que em tempos de retrocessos políticos e sociais aparecem como alternativas contra hegemônicas.
\end{abstract}

Palavras-Chave: Cidade, Interfaces Pedagógicas, Movimento Interfaces, Movimentos Sociais, Resistência.

Resumen

El presente trabajo intenta organizar y sistematizar una relación del evento Interfaces pedagógicas y de su desdoblamiento llamado Movimiento Interfaces, con las actividades y participaciones de movimientos de resistencia y de lucha en la ciudad. Es importante resaltar que las Interfaces Pedagógicas desde el año 2013 se plantea en la perspectiva de fortalecer las licenciaturas y el diálogo de las mismas en la universidad y sus espacios, al mismo tiempo que proponen una interlocución con los espacios más allá de la universidad. El Movimiento Interfaces aparece como complemento a partir del año 2016, para dar continuidad a las

\footnotetext{
${ }^{1}$ Graduando em História Licenciatura; Universidade Federal do Rio Grande; bolsista FAPERGS grupo/RECIDADE; Rio Grande, Rio Grande do Sul, Brasil; felipetbresolin@ gmail.com.

2 Mestrando em Educação; Universidade Federal do Rio Grande; bolsista CAPES grupo/RECIDADE; Rio Grande, Rio Grande do Sul, Brasil; apocalipse5-5@ hotmail.com.

${ }^{3}$ Pós-doutorado em Educação; Universidade Federal do Rio Grande; Rio Grande, Rio Grande do Sul, Brasil; vchaigar@gmail.com. Trabalho apresentado no III Encontro Humanístico Multidisciplinar e II Congresso Latino-Americano em Estudos Humanísticos Multidisciplinares, Jaguarão/RS, Brasil, 2017.
} 
discusiones y reflexiones demandadas. Dicho esto, el trabajo intenta abordar de forma crítica a las contribuciones que se han traído a los acontecimientos por los movimientos sociales insertos en la ciudad y que pueden alertarnos de la epistemología de resistencias y que en tiempos de retrocesos políticos y sociales aparecen como alternativas contra hegemónicas.

Palabras clave: Ciudad, Interfaces pedagógicas, Movimiento Interfaces, Movimientos Sociales, Resistencia

\section{Abstract}

The present work tries to organize and systematize a relation of the event Pedagogical Interfaces and its unfolding called Movement Interfaces, with the activities and participations of movements of resistance and of struggle in the city. It is important to emphasize that the Interfaces Pedagogics since the year 2013 is aimed at strengthening undergraduate degrees and their dialogue in the university and its spaces, while proposing an interlocution with spaces beyond the university. The Interfaces Movement appears as a complement from the year 2016, to continue the discussions and reflections demanded. That said, the paper tries to critically address the contributions that were brought to the events by the social movements inserted in the city and that can warn us about the epistemology of resistances and that in times of political and social setbacks appear as alternatives against hegemonic.

Keywords: City, Pedagogical Interfaces, Movement Interfaces, Social Movements, Resistance.

\section{Contextualização}

O presente artigo é fundamental na perspectiva de defender o espaço de formação que é construído desde o ano de 2013 no Interfaces Pedagógicas, que não vem se destacando em vão, pois o mesmo, é imprescindível dentro de uma lógica produtivista "quanti", aonde a universidade desperdiça uma amálgama de epistemologias, experiências e resistência, que escoa pelo grande ralo da categorização, ao mesmo tempo em que o crivo científico estabelecido, determina de forma verticalizada, ou seja, determinando o que é e o que não é ciência. Destacamos de antemão, que o Interfaces Pedagógicas, e desde 2016, o Movimento Interfaces, não se desfaz em seu âmago da "rigorosidade" (FREIRE, 2017, p.28), mas entendemos que na subjetividade dos sujeitos, que não cabe em categorizações, há algo para além das estacas deterministas do cientificismo, que é ao mesmo tempo monólogo, retrógrado e engessado.

Cabe aqui também, nessa antecâmara, sublinhar que o Interfaces Pedagógicas e o Movimento Interfaces, se fazem de luta e resistência, trazendo as discussões, reflexões e práticas latentes para dentro de si, entendendo que para "além dos muros" há muito conhecimento, e podemos até defender, epistemologias resistentes, construída no cotidiano de cada mulher e de cada homem. Os pontos de vista aqui sistematizados não propõem a "invenção da roda" e de nenhuma maneira se coloca de modo arrogante ou narcisista, mas vêm demarcar a presença dos movimentos sociais, políticos e outros movimentos que possuem concepções de resistência na cidade, no âmbito da formação, reconhecendo que esses sujeitos que lutam pelos imigrantes e os próprios imigrantes que trazem as suas demandas; militantes de partidos, coletivos e sindicatos; militantes e lutadores políticos e 
sociais, apartidários e sem coletivos; militantes dos direitos dos animais e pela libertação animal; estão contribuindo de forma utópica para a construção de um outro mundo, por uma outra lógica, que não se coloca, mas se constrói de forma árdua, porém, contra hegemônica. Nesse caso, ao defendermos tais movimentos por uma linha "utópica", nos acoplamos à Walter Benjamin (1892-1940), pois ao afirmar que precisamos lutar "por um futuro concreto, de utopias realistas, suficientemente utópicas para desafiar a realidade que existe, mas realistas para não serem descartadas facilmente" (apud SANTOS, 2007, p.37), coloca a utopia como uma proposta cheia de convicção que nos permita desafiar as limitações e as condições adversas do presente.

É mister nessa reflexão entender que o Interfaces Pedagógicas, propõem em certa medida uma quebra de paradigma. Como assim? Bem, em tempos de destruição e desmonte da educação pública, de ataques aos professores e professoras em todas as esferas possíveis, dos cursos de licenciatura sofrerem certa marginalização e serem pensados pelos bacharéis, a universidade de modo geral reconhecendo-se unicamente como produtora do conhecimento e legitimadora do mesmo, transformando-o em mercadoria e consequentemente em poder, entender a escola pública como espaço formador e os professores e professoras como protagonistas e produtores/as de conhecimento, é necessário muito esforço, criatividade, práxis e fôlego que tende a uma proposta revolucionária.

Conectado a isso viemos reforçar que para além do espaço escolar e do protagonismo docente da escola, os movimentos presentes no Interfaces Pedagógicas e no Movimento Interfaces denunciam as desigualdades, contradições e discrepâncias, que na maioria das vezes é alarmante e em nosso contexto social quase que abissal! Por isso se faz imprescindível a presença dos mesmos movimentos e sujeitos nos espaços não somente dos dois eventos citados, mas também na universidade como um todo, que de forma preponderante conversa de si para si, e também produz sobre a população e sobre a comunidade sem o consentimento das mesmas.

Para isso, entendemos que esses outros sujeitos, homens e mulheres que fazem da sua vida uma resistência, são a prova de que a desigualdade e as opressões que se aprofundaram durante o século XX e XXI, produziram uma explosão de lutas e resistências, que nos alertam sim, para outras epistemologias. Miguel Arroyo ratifica isso:

Quem são essas populações que tomaram consciência política a ponto de tornar o século XX e continuar tornando o início do XXI os mais revolucionários de nossa história? Em nossas sociedades latino-americanas são grupos sociais que se fazem presentes em ações afirmativas nos campos, nas florestas, nas cidades, questionando as políticas públicas, resistindo à segregação, exigindo direitos. Inclusive o direito à 
escola, à universidade. São os coletivos sociais, de gênero, etnia, raça, camponeses, quilombolas, trabalhadores empobrecidos que se afirmam sujeitos de direitos. Outros sujeitos. São seus filhos e suas filhas que se fazem presentes nas escolas públicas e que exigem o acesso às universidades. São outros educandos. A tomada de consciência dessas populações mantidas por séculos sem direito a ter direitos ao teto, à terra, á saúde, à escola, à igualdade e à cidadania plena se fazem presentes em ações e movimentos, em presenças incômodas que interrogam o Estado, suas políticas agrárias, urbana, educacional. Interrogam a docência, o pensamento pedagógico, as práticas de educação popular e escolar. (ARROYO, 2014, p.09)

Tanto o Interfaces Pedagógicas e o Movimento Interfaces, estão definitivamente abertas para esses sujeitos que se colocam perante o mundo através de suas lutas, materializados em seus movimentos, coletivos, partidos e organizações. Essa condensação de reivindicações se coloca como rupturas de um processo de educação e pedagógico hegemônico, ou como falamos nas discussões entre e nas licenciaturas, fogem da tentativa que se tem de formar professoras e professoras que vão trabalhar com alunos e alunas "ideais", destoante dos alunos e alunas das camadas populares, que possuem outras demandas.

Esse artigo foi construído por sujeitos que militam, trabalham e também pesquisam, e por isso trazem apontamentos, reflexões e questionamentos de suas experiências, mas as mesmas categorias, são consideráveis para a construção do conhecimento, e para a construção de uma perspectiva pedagógica crítica. Felipe Bresolin é acadêmico do curso de História Licenciatura, militante do movimento estudantil na FURG e atualmente trabalha como educador substituto e parceiro do Instituto de Educação Josué de Castro ${ }^{4}$, construído e organizado pelo Movimento dos Trabalhadores Rurais Sem Terra (MST) ${ }^{5}$ na cidade de Veranópolis. Samuel Ferreira é também acadêmico do curso de História Licenciatura e mestrando do PPGEDU-FURG, trabalha e pesquisa Educação Popular e está finalizando a dissertação, que é resultado de sua pesquisa que tem por título "E Se a Cidade Fosse Nossa: A Educação Popular Contribui na Emancipação e Humanização das Juventudes na Cidade?”. Ambos compõem o Recidade - Rede de cultura, estética e formação na/da cidade ${ }^{6}$ - e estão encharcados e transpassados pelas lutas e resistências que vão ao encontro dos movimentos sociais e outros grupos de resistência que lutam pela transformação e emancipação humana. Construído por jovens estudantes de Licenciaturas e mestrandos em educação da Universidade Federal do Rio Grande - FURG, o Recidade trata-se a bem da verdade de uma

\footnotetext{
${ }^{4}$ Pensador e ativista político brasileiro, engajado na quebra de falsas convicções de que a fome e a miséria do mundo eram resultantes do excesso populacional e da escassez de recursos naturais.

${ }^{5}$ Movimento social brasileiro que tem como principal foco as questões dos trabalhadores do campo, principalmente no tocante à luta pela reforma agrária brasileira.

${ }^{6}$ Por força de expressão, os próprios integrantes chamam Recidade de GRUPO, mesmo ele sendo uma linha de pesquisa dentro do Educamemória.
} 
linha de pesquisa, articulada ao EDUCAMEMÓRIA - Núcleo de Pesquisa e Extensão Educação e Memória, sediado no Instituto de Educação, mas que atua de forma independente e reúne distintas áreas do conhecimento das licenciaturas, como Arte, Letras, História, Pedagogia e Matemática, além de mestrandos. O respeito às trajetórias identitárias de cada um/a, o incentivo à criação e ao protagonismo são características que vem se firmando à medida que vai sendo desenhado no mapa das ações de ensino, pesquisa e extensão da instituição que o abriga. Essas peculiaridades levam seus membros a reivindicá-lo como grupo, tatuando-o com linguagens próprias como seu símbolo, explicitado em uma sombrinha ao contrário, cuja copa é dada pelas águas da Laguna dos Patos que banha a cidade, uma criação do coletivo. Como "grupo" tem uma história de vida recente. Surgiu em 2016, embora o Núcleo exista desde 2010 (atualmente é constituído por duas linhas: uma que atua/estuda o/no campo e outra que atua/estuda a/na cidade), e a cidade tomada como espaço educador vem sendo enfatizada desde 2006, sobretudo no curso de Licenciatura em Pedagogia, em que mais de sessenta (60) investigações foram realizadas por licenciandos/as. Com o surgimento do Curso de Pós-Graduação em Educação em 2012, passaram a ocorrer também pesquisas no mestrado acadêmico, assim como ações de extensão como o atual Proext/2016 "Cultura, Estética e Formação: redes de saberes, incompletudes e territorialidades" associado as demais atuações que envolvem o ensino e a pesquisa.

\section{Objetivos}

Os objetivos desse trabalho são especificamente dois. O primeiro é destacar a importância e a relevância do Interfaces Pedagógicas e o seu desdobramento, Movimento Interfaces, como espaço de diálogo das licenciaturas e educação, formal, não formal e informal, e sua responsabilidade e intencionalidade formativa. Os dois eventos, ao proporcionarem esse diálogo, caminham na contramão de um modus operandis que vem desqualificando ano após ano a profissão professora/professor, fazendo com que os mesmos façam de sua profissão quase que uma trincheira, para se defender o que se conquistou até agora e para tentar não recuar e não retroceder. Na universidade, tem se efetuado cada vez mais a desintegração e a fragmentação de currículos das licenciaturas, a destruição de programas que fomentam a iniciação à docência e outros ataques propriamente do capital encabeçado pelo empreendedorismo que beneficiam outros ramos da produção científica. $\mathrm{O}$ Interfaces Pedagógicas e o Movimento Interfaces são parte do contraponto a tudo isso, pois tenta através da relação entre escola, cidade e universidade, fortalecer as bases de uma educação transformadora, porém, essa resistência se dá de modo micro, nas coisas pequenas e 
simples. Portanto, o Recidade, que é o "movimento" que constrói tanto o Interfaces Pedagógicas quanto o Movimento Interfaces, está incumbido dessa tarefa pequena e local que está ligada à educação, mas que desafia de modo contundente a realidade. E essas tarefas pequenas são imprescindíveis como ainda nos convence Paulo Freire:

Sei que o ensino não é alavanca para a mudança ou a transformação da sociedade, mas sei que a transformação social é feita de muitas tarefas pequenas e grandes, grandiosas e humildes! Estou incumbido de umas dessas tarefas. Sou um humilde agente da tarefa global de transformação. (FREIRE; SHOR, 1991, p.60)

O segundo é perceber a potencialidade epistemológica desenvolvida pelos sujeitos desses movimentos sociais, políticos e outros, na integração e construção de uma educação que traga outras indagações e outros pontos de vistas, que caminhem para um viés contra hegemônico e emancipador. É entender através de sua postura afirmativa e intensa, aspectos que refazem o próprio conhecimento, os princípios educativos e pedagógicos e contestam o próprio lugar que a sociedade delimitou para eles mesmos.

\begin{abstract}
Disputar os próprios espaços de produção, sistematização do conhecimento, confrontar seus conhecimentos, sua racionalidade, seus critérios de validade com os conhecimentos, a racionalidade, os critérios de validade pensados como únicos, legítimos é algo muito novo nos novos sujeitos sócias. Mudam a direção em que o pensamento válido por intelectuais comprometidos aos espaços criados de conscientização, cultura, educação. Aí nasceram pedagogias radicais. Ao mudarem de direção os coletivos populares se sabem como outro olhar diferente do olhar com que foram pensados, com outros saberes, com Outras Pedagogias. Sabem-se mais feitos e conscientes do que como foram pensados para ser subordinados e até conscientizados. O movimento que se propõe educa-los vai de cá para lá, o movimento atual dos coletivos populares é de lá pra cá. Fazendo-se presentes, com uma afirmação positiva no campo, na cidade, na política, nos centros de cultura e de conhecimento. Um movimento de diálogo horizontal no reconhecimento. (ARROYO, 2014, p.58)
\end{abstract}

Miguel Arroyo vem ressaltando algo que vem sendo efetuado, uma prática que tem se intensificado com a luta por direitos daqueles que não possuem direitos. Ou como diriam os historiadores marxistas E.P. Thompson e Eric Hobsbawm, a história vista de baixo ${ }^{7}$, por aqueles e aquelas que fazem de sua vida uma coluna de sobrevivência. Esses que vem "de baixo", esses "outros sujeitos", tem muito o que nos dizer, e defendemos aqui nesse artigo, que suas lutas e resistências são a construção real de conhecimentos, e que servirá como pressupostos epistemológicos contra hegemônicos.

\footnotetext{
${ }^{7}$ Em vários de seus textos, E.P. Thompson defenderá a "history from bellow". Um exemplo está em As peculiaridades dos ingleses e outros artigos (Campinas, Editora da Unicamp, 2010) e no caso de Eric Hobsbawm, encontramos algo diretamente sobre em "A história de baixo para cima" em Sobre história: ensaios (São Paulo, Companhia das Letras, 1998).
} 


\section{Movimentos sociais, políticos e outros que construíram o Interfaces Pedagógicas e o}

\section{Movimento Interfaces em 2018}

Seguindo o objetivo de proporcionar e construir espaços de formação quepotencialize a discussão e o protagonismo de grupos e movimentos na e da cidade,o Interfaces Pedagógicas e o seu desdobramento Movimento Interfaces, no ano de 2018contou com movimentos e sujeitos plurais na realização dos espaços. A Tabela 1 mostra os respectivos movimentos:

Tabela 1 - Movimentos sociais, políticos e outros que construíram o Interfaces Pedagógicas e o Movimento Interfaces em 2018

\begin{tabular}{|c|}
\hline Mobilizações sociais, movimento negro e a educação de crianças. \\
\hline Militantes dos direitos dos animais e pela libertação animal \\
\hline Culturas e Saberes Ancestrais \\
\hline Estudantes Estrangeiras (Honduras e Palestina) \\
\hline Movimento Nacional de luta por Moradia \\
\hline Pastoral do Migrante
\end{tabular}

Fonte: Seminário Interfaces Pedagógicas

Nesse sentido, buscou-se além de construir um espaço de formação contra hegemônico de forma coletiva e horizontal com grupos historicamente invisibilizados na cidade, também trabalhar com um pensamento crítico frente à luta do movimento e "da indignação, da "justa ira" dos traídos e dos enganados. Do seu direito e do seu dever de rebelar-se contra as transgressões éticas de que são vítimas cada vez mais sofridas" (FREIRE, 2011, p.99).

\section{Conclusão}

Compreendemos na reflexão e na organização desse artigo à importância da construção de formas e de espaços de saber, no caso do Interfaces pedagógicas e do movimento Interfaces, aonde os movimentos sociais, coletivos e outras organizações se fazem presentes e colocam as suas demandas em evidência. Esses espaços dos eventos são imprescindíveis, pois como nos fala Maria da Glória Gohn, "constituem um instrumento poderoso das classes populares, no sentido de atingirem seus objetivos" (GOHN, 1994, p.51), buscando mobilizar e gerar inquietações que põem em risco os poderes e saberes hegemônicos, e construindo epistemologias e conhecimentos para além da educação e da pedagogia formalmente desenvolvida.

Assim, trabalhar e construir espaços que tragam vozes invisibilizadas da cidade, ao mesmo tempo em que se torna uma ameaça às classes dominantes, também surge 
como uma necessidade para resistir aos ataques reacionários e lutar para que os direitos alcançados com muita luta sejam mantidos. Reivindicando cada vez mais em espaços de formação e diálogo entre movimentos e licenciados, para a idealização e organização de sujeitos engajados e enraizados nas práticas políticas e sociais que envolvem a cidade.

\section{Referências}

ARROYO, Miguel. Outros Sujeitos, Outras Pedagogias. 2.ed. - Petrópolis, RJ: Vozes, 2014.

FREIRE, Paulo. Pedagogia da Autonomia: saberes necessários à prática educativa. 43.ed. São Paulo: Paz e Terra, 2011.

FREIRE, Paulo; SHOR, Ira. Medo e Ousadia: o cotidiano do professor. 12. Ed. São Paulo: Paz e Terra, 1984.

GLOHN, Mária da Glória Marcondes. Movimentos sociais e educação. 2.ed. São Paulo: Cortez, 1994.

SANTOS, Boaventura de Sousa. Renovar a Teoria Crítica e Reinventar a Emancipação Social. São Paulo: Boitempo, 2007. 